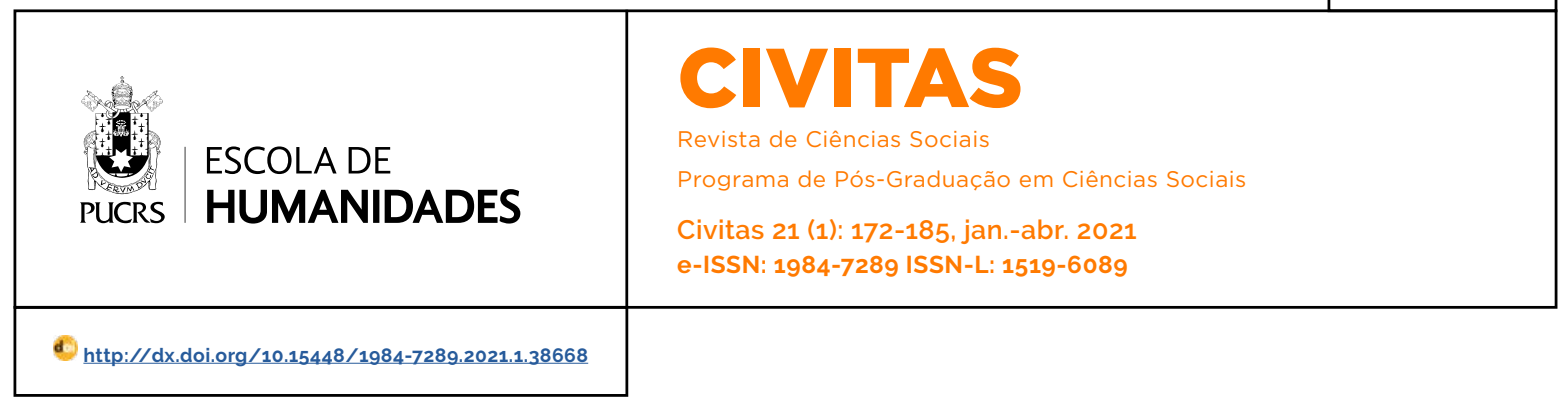

SEÇÃO: ARTIGOS/ARTICLES

\title{
Cidadania local e a volatilização do político examinadas através de exemplos de participação em propostas de planejamento urbano
}

\author{
Local citizenship and volatility of politics examined through examples of participation in \\ urban planning proposals
}

Ciudadanía local y volatilidad de lo político examinados a través de ejemplos de participación en propuestas de planificación urbana

\section{Chantal Magnin ${ }^{1}$}

orcid.org/0000-0002-8163-5408

chantal.magnin@hslu.ch

Recebido em: 22 jul.2020. Aprovado em: 3 dez. 2020. Publicado em: 7 maio. 2021.

\section{(c) (i)}

Artigo está licenciado sob forma de uma licença Creative Commons Atribuição 4.0 Internacional.
Resumo: Em vista da globalização, da migração e da urbanização, o significado da cidadania muda, mesmo que seu conteúdo normativo, isto é, os direitos humanos e os deveres a ela associados, não mudem diretamente. Neste artigo, serão perseguidas algumas possiveis transformações da cidadania em direção a um fortalecimento da referência local. Como e em que contexto emerge uma cidadania urbana? Como é sabido, o Brasil é o único país em que o direito à cidade está inscrito na Constituição. À luz das transformações referidas, no artigo são examinados resultados escolhidos de uma pesquisa a respeito das experiências de cidadãs e cidadãos em procedimentos de participação em propostas de planejamento urbano na Alemanha e na Suiça. Mesmo que tais fóruns participativos sejam importantes para a formação de opinião pública, é evidente uma perda de importância da política em face aos interesses privados, de modo que a cidadania local é colocada em questão.

Palavras-chave: Cidadania urbana. Participação pública. Planejamento urbano. Sociologia urbana.

Abstract: In the course of globalization, migration, and urbanization, the meaning of 'citizenship' undergoes a change, even though its normative core - that is, the human rights and the related duties - do not directly change. The present paper follows some possible transformations of citizenship which are directed to strengthening local ties. How and in which context does a local citizenship emerges? As is well known, Brazil is the only country, in which the right to the city is inscribed in the National Constitution. In light of the mentioned transformations, this article examines selected results of a research about citizens experiences in participatory procedures for urban planing proposals in Germany and Switzerland. Although such participatory forums are important for public opinion formation, it is clear that politics meaning decay in face of private interest, so that local citizenship might be questioned.

Keywords: Local citizenship. Public participation. Urban planing. Urban sociology.

Resumen: En vista de la globalización, la migración y la urbanización, el significado de ciudadania cambia, incluso si su contenido normativo, es decir, los derechos y deberes humanos asociados con él, no cambian directamente. En este artículo, se buscarán algunas posibles transformaciones de la ciudadanía hacia un fortalecimiento de su referencia local. ¿Cómo y en qué contexto surge una ciudadania urbana? Como es bien sabido, Brasil es el único pais en el que el derecho a la ciudad está incluido en la Constitución. A la luz de las transformaciones mencionadas, el artículo examina resultados elegidos de una encuesta sobre las experiencias de los ciudadanos y ciudadanas en los procedimientos para participar en propuestas de planificación urbana en Alemania y Suiza. Aún que tales foros sean participativos importantes para la formación de la opinión 
pública, existe una evidente pérdida de importancia de la política frente a los intereses privados, por lo que se cuestiona la ciudadania local.

Palabras clave: Ciudadanía urbana. Participación pública. Urbanismo. Sociología urbana.

\section{Introdução²}

À primeira vista, os direitos humanos e a cidadania moderna são dois conceitos diferentes que, porém, tomados cada um por si, são de significado fundamental para a democracia moderna. Ambos asseguram a participação política de cidadãs e cidadãos. Ainda que possam, de algum modo, estar conectados, eles não se reduzem totalmente um ao outro: direitos humanos podem ser entendidos, de uma forma totalmente reduzida, como simples direitos de proteção contra a violência arbitrariamente exercitada pelo estado, enquanto cidadania assegura a participação na formação politica da vontade - e, em democracias ocidentais, também assegura a participação no bem-estar, através da cidadania social. Se essa última se revela como fortemente desenvolvida em um estado ou comunidade política, ela entra em uma relação tensa, especialmente com a liberdade política do individuo, assegurada através dos direitos humanos. Em cada estado nacional democrático essa tensão se manifesta de uma maneira particular. Se se trata antes de uma democracia liberal-representativa ou de uma democracia mais direta-participativa, isso sempre dependerá, também, das práticas democráticas de formação da vontade política possibilitadas pelas condições gerais de ação.

No que concerne à ligação de ambas as abordagens na teoria, Seyla Benhabib ofereceu uma sugestão interessante: ela argumenta que, em seu significado, direitos humanos sempre apontam para além de seu contexto e, apesar disso, são moldados por ele, ainda que de formas diferenciadas. Então, seria a "linguagem dos direitos humanos" que superaria essa dicotomia:

Em democracias, é particularmente o discurso que se movimenta necessariamente dentro da tensão gerada de um lado pela dimensão valorativa dos direitos humanos que transcende o contexto e a comunidade, e a codificação e legislação historicamente marcadas, culturalmente criadas e societariamente modeladas de comunidades jurídico-civis existentes, por outro. (Benhabib 2016, 69).

Benhabib vê a "função dos direitos humanos transcendente ao contexto" (Benhabib 2016, 11) fundada, em última instância, na garantia do exercício da liberdade comunicativa (Benhabib 2016, 61), que consiste em poder convencer os outros de nossos próprios argumentos. Isso significa ao mesmo tempo admitir que existe uma necessidade universal de comunicação dos humanos que não se relaciona somente aos próprios interesses imediatos, mas que se refere à convivência com outros e, portanto, deve ser vista em um horizonte de sentido maior do que unicamente no âmbito da realização da felicidade individual. ${ }^{3}$ Para que a solução coletiva de problemas possa ser realizada em uma comunidade sob a condição de possibilidades igualitárias de participação é necessária a garantia de um "direito a ter direitos", como Benhabib $(2016,61)$ formula seguindo Hannah Arendt.

Mesmo que Benhabib, em primeira linha, queira mostrar que os direitos humanos podem e até devem manifestar diferentes conformações, dependendo do respectivo contexto, para que eles possam receber aceitação universal, isso significa também que tal garantia da comunicação humana - no sentido de uma prática social - deve ultrapassar a preservação de liberdades mínimas de

\footnotetext{
2 Traduzido por Luiz Gustavo da Cunha de Souza (Universidade Federal de Santa Catarina, Ufsc, Florianópolis, SC, Brasil) e Emil A. Sobottka (Pontificia Universidade Católica do Rio Grande do Sul, Pucrs, Porto Alegre, RS, Brasil).

3 Isso também defendem teóricos importantes para a compreensão sociológica fundamental, tais como, por exemplo, Émile Durkheim Talcott Parsons e George Herbert Mead. Eles enfatizam que só através da relação reciproca com outros, produzida por meio da comunicação, os humanos podem experimentar a si mesmos como presentes em um horizonte de sentido mais amplo. Exatamente isso é o que Benhabib conecta com os princípios normativos da vida humana comunitária moderna - isto é, os direitos humanos. Em Parsons, a comunicação, e, assim, o convencimento argumentativo de outros, desempenha do mesmo modo um papel importante: "The ideal type of the democratic association, including that of the politically organized society as a whole, is built on the principle that all full members are basically equal, as expressed in the principle of equal freedom to communicate (hence attempt to persuade) and equality of the franchise on the basis of one member, one vote" (Parsons 1969, 505).
} 
imprensa e opinião. Ela exige, também, a garantia de direitos à participação e, assim, direitos de cidadania política. ${ }^{4}$ Hoje essa garantia se realiza no exercício prático e na realização dos direitos e dos deveres associados à cidadania nacional. ${ }^{5}$ Todavia, em vista de globalização, migração e urbanização, o significado dessa cidadania muda, mesmo que seu conteúdo normativo, isto é, os direitos e os deveres a ela associados, não mudem diretamente. Todavia, mesmo neles pode haver ajustes.

Nesse artigo serão perseguidas possiveis transformações da cidadania em direção a um fortalecimento da vinculação com o contexto local. Como e em que contextos se manifesta uma cidadania urbana (urban citizenship)? No artigo alguns resultados selecionados de uma pesquisa a respeito das experiências de cidadãs e cidadãos em procedimentos de participação em planejamento urbano ligado a edificações na Alemanha e na Suiça, são submetidos a uma análise mais acurada à luz dessa questão. ${ }^{6} \mathrm{Com}$ isso se mostrará que, de fato, é possivel identificar localizadamente iniciativas de uma cidadania urbana também por meio de possibilidades aumentadas de participação. Ao mesmo tempo, porém, mostra-se, em parte, que discussões políticas e soluções derivadas delas não apenas são secundarizadas com relação à extração de valor econômico, como também perdem relevância frente a ela. Com isso, a cidadania política se torna questionável. A personagem da cidadã, do cidadão, ameaça desaparecer do palco. O planejamento participativo organizado por autoridades antes pode ocorrer bem justamente lá onde a municipalidade dispõe do necessário poder de influência. E esse nem sempre é o caso.

\section{Transformação da cidadania entre referência local e o estado nacional}

Um entendimento de "cidadania" se desenvolveu pela primeira vez comprovadamente na cidade-estado ateniense. Ela designava o pertencimento à polis, à comunidade política, que sabidamente não incluía todos na mesma medida. Hoje, porém, a cidadania, em sua forma moderna e universalista, está inevitavelmente conectada com a ordem político-jurídica moderna estabelecida sobre o território do estado nacional chamada "democracia" e, portanto, com pertencimento a um estado nacional. Este último, então, está ligado à soberania, cuja importância já há muito tempo se tornou frágil devido à globalização. Se a politica nacional perde importância em vista da necessidade de solução política de problemas em contextos internacionais e, em tempos neoliberais, também face às relações econômicas patrocinadas e aos serviços prestados pelo mercado, então isso também tem efeito sobre as possibilidades de influência através da cidadania nacional. Essas possibilidades, por conseguinte, se tornam menores. Já as possibilidades locais, ao menos à primeira vista, parecem se tornar ao mesmo tempo maiores. Assim, diferentes indicações e aspectos sugerem a emergência de uma assim chamada urban citizenship, em paralelo a uma cidadania global que possivelmente também esteja se desenvolvendo. Assim, Benhabib tematiza o duplo impacto de uma cidadania ancorada no universalismo. De acordo com ela, a globalização leva não apenas a uma mudança da soberania estatal e do estado de direito, mas do mesmo modo a uma reformulação da cidadania em âmbito local. O que hoje se discute, acima de tudo no contexto de pesquisas sobre migração, deverá ser relacionado aqui mais fortemente com

\footnotetext{
4 Ao diferenciar entre demandas jurídicas e catálogo de direitos, Benhabib se associa a Jürgen Habermas. Segundo seu argumento, os direitos individuais somente podem ser assegurados sobre a base de uma garantia fundamental de constitucionalidade (sobre isso, ver Habermas 1992, 109 et seq., 285 et seq.).

5 Também é interessante que em John Rawls e no catálogo de direitos modernos por ele elaborado, de acordo com Benhabib (2016, 53), não está contido nenhum direito à participação. O direito humano à "autodeterminação política", diz Benhabib, é deixado de lado "sem comentário" por Rawls. Esse direito estaria assegurado no artigo 21 da Declaração Universal dos Direitos Humanos como direito a tomar parte na "direção dos negócios públicos do seu pais, quer diretamente, quer por intermédio de representantes livremente escolhidos".

6 O projeto com o titulo Bürger_in aus Betroffenheit? Zum Wandel von politischen Ordnungsvorstellungen am Beispiel von partizipativen Foren zu städtebaulichen Vorhaben und ihren Teilnehmerinnen und Teilnehmern in Deutschland und der Schweiz" [Cidadãos por consternação? Sobre a mudança nas concepções de ordem politica através de exemplos de fóruns participativos a respeito de propostas de planejamento urbano e de seus participantes na Alemanha e na Suiça] foi financiado pela Deutsche Forschungsgemeinschaft (DFG), realizado entre os anos de 2014 e 2017, e esteve vinculado ao Instituto de Pesquisa Social (Institut für Sozialforschung), em Frankfurt am Main.
} 
o tema da vida urbana. Essas perspectivas sobre uma cidadania local devem ser vistas, também, como um "direito à cidade", como foi concebido por Henri Lefebvre (2016 [1968]) nos anos 1960? E as possibilidades de participação em workshops e outras atividades do planejamento participativo em propostas de planejamento urbano devem ser vistas como uma prática resultante desse direito?

\section{Cidadania conectada à residência?}

Com isso já se toca no tema da migração, que desempenha um papel central na questão de uma cidadania urbana e local. A ideia da cidadania local desfruta de grande popularidade. acima de tudo no contexto da pesquisa e da discussão sobre a migração. Quando, hoje, através das autoridades se abrem possibilidades de participação, também em relação a serviços de seguridade social e da assiduidade de crianças à escola, inclusive para estrangeira(o)s sem direito à residência, elas podem ser compreendidas conceitualmente como aspectos de uma cidadania urbana. Elas servem à integração em âmbito local. É a resposta ao problema da atribuição do direito à cidadania nacional. Bosniak (2006, 34) fala aqui também de uma citizenship of aliens (cidadania de estrangeiros). Localmente trata-se, então, de assegurar integração tanto em vista do uso de instituições públicas como também da moradia para migrantes. Devido a essas conexões, os problemas da cidadania nacional são discutidos acima de tudo em vista de migração e de globalização (p. ex., Castles e Davidson 2000; Albiez et al. 2011). Essa problematização é orientada por um interesse nas relações internas das sociedades em referência a questões de justiça distributiva, e se orientam em última instância à social citizenship (cidadania social). Por meio dela deveriam ser garantidas também as participações econômica e social, como Thomas H. Marshall (1992 [1950]) as desenvolveu em seu trabalho. Ao mesmo tempo, se desenvolve, assim, algo como uma garantia de possibilidades políticas de participação descoladas do pertencimento nacional, como, por exemplo, no assim chamado "direito de voto dos estrangeiros" no nivel comunal na Alemanha para cidadãs e cidadãos da União Europeia. Neste assim chamado "direito de voto dos estrangeiros" - na Alemanha, para cidadãs e cidadãos da União Europeia - isso já é rudimentarmente realizado. Porém, também na Suiça, que não é membro da UE, existe um direito ao voto e sufrágio para "estrangeiras e estrangeiros" nos dois cantões de Neuenburg e Jura. Esse direito não se restringe a eleições comunais, mas também vale em eleições e votações cantonais. A condição é uma certa duração da permanência. Devido à construção fortemente decentralizada e federalmente marcada da formação do estado na Suiça, os cantões e comunas são livres para decidir se querem atribuir o direito ao voto e ao sufrágio a estrangeira(o)s em nivel comunal. Outros cantões, além dos dois mencionados, também já enveredam pela citada direção. ${ }^{70}$ motivo para esse desenvolvimento é um declínio da segurança garantida por meio da cidadania frente à violência e à barbárie em outros lugares. A isso Castles e Davidson $(2000,228)$ já apontaram no ano 2000, e mencionavam como exemplos da perda de controle estatal em regiões do mundo como o Afeganistão, o Congo e, devido à criminalidade econômica, na Colômbia. Por meio da migração, cidadãs e cidadãos se afastam de sua comunidade jurídica devido à falta de proteção frente ao arbitrio estatal, e se estabelecem em um lugar onde a comunidade jurídica residente os aceita apenas sob certas condições. Como isso ocorre cada vez mais frequentemente, coloca-se a pergunta sobre se a cidadania nacional como ideia para o regramento da participação não deveria ser generalizadamente relativizada. A perda de segurança pode ser vista como gatilho para isso. Por isso é interessante que Beauregard e Bounds (2000, 249), em conexão com sua ideia de uma cidadania urbana, mencionam primeiro

\footnotetext{
Aos dois se somam os cantões de Waadt e Freiburg, nos quais estrangeiras e estrangeiros podem sufragar, votar e ser votados sob certas condições não em questões cantonais, porém em todas as comunas. Nas comunas do cantão de Genebra as estrangeiras e estrangeiros dispõem, em contraste, apenas do direito passivo de voto, mas não do ativo. Na Suiça alemã apenas algumas comunas isoladas introduziram o direito ao voto e ao sufrágio comunais, como nos cantões Graubünden e Appenzell Ausserrhoden.
} 
a garantia de segurança. Cidadania urbana significa, para eles, uma "thick relationship between the users of cities and the public realm of cities" (Beauregard e Bounds 2000, 243). Ainda que esses autores não sustentem explicitamente, a isso pertence também o aspecto de que cidadãs e cidadãos fortalecem sua ligação na medida em que podem decidir sobre o âmbito público das cidades. Uma tal identificação com construções e modelagens do espaço vai além da questão de como espaços poderão ser ocupados individualmente no futuro. Vista desse modo, a participação em eventos sobre o tema pode muito bem ser entendida como parte de uma cidadania urbana. Ao mesmo tempo, essa participação não está ligada ao pertencimento nacional e, logo, a uma cidadania nacional, o que também permite a participação de concernidos que não dispõem dela. Só que essa possibilidade justamente quase não é utilizada por migrantes; isso também se confirma nos casos que estudamos. Inversamente, esse acesso fundamentalmente aberto significa justamente que não existe qualquer compromisso formal de levar os resultados de discussões em consideração no processo de decisões políticas.

Para as e os migrantes uma cidadania urbana como a concebem Beauregard e Bounds significaria que, por meio dela, eles justamente não seriam mais "extraterrestres", mas sujeitos equipados com direitos políticos. Eles estariam, assim, vinculados ao território municipal. Combina com isso que principalmente centros urbanos estejam em busca de novas formas de possibilidade de participação, desconectadas de uma cidadania garantida pelo estado nacional. Como um dos mais proeminentes exemplos correntes pode ser mencionado aqui o "New York Card", que permite a moradoras e moradores utilizarem as instituições públicas, mesmo que não disponham de qualquer status de residência juridicamente reconhecido. Trata-se, pois, de uma descriminalização parcial da residência dos indocumentados. As autoridades da cidade suiça de Genebra enveredam por uma direção parecida quando, através da "Operation Papyrus", regularizaram a residência de milhares de "Sans Papier". ${ }^{8}$ Através disso, o lugar de moradia recebe, em geral, mais peso como ponto de partida de práticas democráticas. Direitos à participação democrática, que de modo inovador estejam ligados ao lugar de moradia ou de vida, foram demandados na "Charta von Palermo für globale Bewegungs- und Niederlassungsfreiheit" (Carta de Palermo pela liberdade e movimento e estabelecimento), iniciada pelo então prefeito de Palermo e político, escritor e ator Leoluca Orlando em 2015. Como primeiro ponto consta nela a exigência por uma cidadania do lugar de moradia.

Ao menos pontualmente mostra-se, pois, um desenvolvimento em direção a uma cidadania que está ligada a territórios menores do que o estado nacional. Isso pode ser entendido tanto como retrocesso quanto como progresso. Mas há nisso uma conexão com o slogan de "direito à cidade", como remonta a um escrito de Henri Lefebvre do ano de 1968? Aquele slogan recebe hoje em dia nova atualidade, mas provavelmente menos por causa da perda de significado do estado nacional nos últimos anos, e mais devido ao crescimento da atratividade econômica dos centros das cidades. Marcuse (2009) descreve o "direito à cidade" como um tipo de metáfora e de designação sumária para demandas e apropriações bastante diferentes relativas ao espaço urbano. Hoje, atividades como a jardinagem urbana ou, também, a ocupação de imóveis, são vistas como práxis de tal forma de apropriação, por meio das quais também se trata de não relegar espaços urbanos somente aos interesses privados da extração econômica de valor ou da especulação com o solo. Mesmo que a demanda por um direito à cidade que iniba tais desenvolvimentos ocorra desconectada da cidadania nacional, ainda assim ela se encontra normativamente conectada com uma compreensão universal de democracia. A sociedade civil local também constitui como ponto de ligação. David Harvey (2008), Margit Mayer (2009) e Peter Marcuse (2009) atualizaram

8 Em oposição a isso está a iniciativa do Parlamento Suiço, que pretende tornar mais rígidas as determinações jurídicas contra os indocumentados, de modo que, por exemplo, demandas a respeito da seguridade social thes sejam barradas, mesmo quando estejam empregados. 
esse conceito novamente para a pesquisa. Atualmente pode ser observado um aguçamento de interesses: de um lado, a renovação de centros de cidades impulsionada por investidores, e, de outro lado, as ações de protesto que se voltam contra isso. Reivindica-se um direito ao acesso coletivo e público aos espaços urbanos, que se encontra ameaçado pelas atuais renovações levadas a cabo pelos interesses dos investidores. Os workshops organizados pelas autoridades para tematizar propostas pontuais de planejamento urbano se encontram em algum lugar entre esses interesses e representam uma tentativa de mediação, por um lado, entre as demandas por direito e os interesses econômicos, e, por outro, entre estado e sociedade. Essa tentativa representa, no entanto, sob uma perspectiva completamente diferente, um grande desafio, que ela só conseguirá vencer muito excepcionalmente. Pelo menos é o que sugerem os resultados de nossa pesquisa. Nos seis casos de participação em propostas de planejamento urbano investigados por nós, isso somente deu certo no desenvolvimento das Konversionsflächen em Heidelberg. ${ }^{9}$ A Organização para a Cooperação e Desenvolvimento Econômico (OCDE) tem em mente uma concepção um pouco diferente de "empowerment", através de uma cidadania local voltada, sobretudo, para seres humanos vivendo na pobreza, ainda assim digna de menção. Segundo a argumentação de Catherine Dom, trata-se, no caso, menos de práticas de apropriação do espaço local do que de boa governança, que necessita dos ingredientes "participação, compreensibilidade e inclusão" em decisões políticas: "Effective and inclusive local citizenship means that all people can participate in local decision making processes and hold others to account" (Dom 2012, 111). Através da realização dos mencionados princípios, pessoas socialmente prejudicadas poderiam ser levadas a melhorar suas condições de vida. Ainda que por motivos políticos possivelmente seja inadequado querer relacionar ideias da OCDE com aquelas de Lefebvre, quando se faz isso assim mesmo, pode-se reconhecer interseções entre elas, sobretudo nas formas de manifestação empírica: em ambas perspectivas - tanto para aquelas de baixo (direito à cidade), quanto para aquelas de cima (empowerment) - o lugar onde se está assentado, isto é, a vinculação e a identificação com as condições fisicas e materiais dadas, deverão ser tomadas como ponto de partida para o empoderamento político do sujeito político "cidadão". Isso pressupõe, entretanto, algo como política com as correspondentes possibilidades de ação. O cidadão e a cidadã só são concebíveis como sujeitos politicamente atuantes se existirem problemas e espaços públicos. Se, ao invés disso, os centros das cidades fossem cedidos somente aos interesses econômicos, aquilo que - também para esses últimos - torna os centros atrativos, a saber, uma vida urbana atraente e culturalmente diversificada, em breve desapareceria. Esterilidade e monotonia marcariam, então, a imagem da cidade no futuro. Hoje, porém, existem empresas que realocam suas sedes para centros de cidades, pois assim se tornam mais atrativas como empregadoras para a força de trabalho especializada que desesperadamente buscam.

No Brasil, como uma exceção, o "direito à cidade" contém mais do que apenas um significado metafórico. Esse é um direito ancorado na constituição e reconhecido através de determinações legais. Segundo Eibs Cafrune (2016, 49), as reivindicações nele contidas encontram reconhecimento institucional sobretudo no assim chamado "Estatuto das Cidades", uma lei federal promulgada em 2001. Ele enxerga ali como prioridade a regularização de ocupações informais (Cafrune 2016, 52). Porém, no Estatuto também estão fundamentadas reivindicações como "o direito à moradia, direitos para população de rua, a demanda por qualidade dos meios de transporte público e de mobilidade urbana, a defesa de espaços comuns contra a privatização e a liberdade de expressão" (Cafrune 2016, 47). De acordo com cada contexto, o direito pode assumir formas muito diferentes. Friendly (2013.

9 Foram escolhidas propostas de reforma urbana em Hamburgo (Mitte Altona), Frankfurt am Main (Kulturcampus), Heidelberg (área liberada após a saída do exército dos EUA), Rostock (Warnemünde), Berna (Gaswerkareal) e Basel (Hafenareal). 
158) vê a reivindicação pela co-modelagem da cidade por suas moradoras e moradores ancorada fundamentalmente no "right to participate in the production of urban space". Através desse direito também entram em foco novas formas de apropriação criativa e coletiva do espaço, que, assim, possivelmente alcançam o reconhecimento das autoridades e da política.

Essa política de ancoramento legal de reivindicação por direitos ao uso do espaço e da infraestrutura urbanas por cidadãs e cidadãos remonta aparentemente ao Movimento Nacional pela Reforma Urbana (MNRU), surgido nos anos 1980 de alianças pela liberdade sindical e política. James Holston (2008), antropólogo estadunidense que também se ocupa extensivamente com o tema, descreve as práticas dali emergentes e o reconhecimento institucional que as acompanha como "insurgent citizenship". Segundo ele, tratava-se, acima de tudo, da perenização de moradias nos arredores dos centros de grandes cidades brasileiras por classes empregadas na indústria (Holston 2008, 4). O autor nomeia quatro condições para esse tipo de "urban citizenship":

when urban residence is the basis of mobilization, right claims addressing urban experience compose their agenda, the city is the primary political community of reference of this developments, and residents legitimate this agenda of rights and participatory practices on the basis of their contributions to the city itself. (Holston 2008, 23).

No fundo trata-se de uma forma societariamente aceita e, em parte patrocinada, de autogestão, como historicamente também se estabeleceu na construção cooperativa de moradias pela classe trabalhadora em cidades da Europa ocidental. Também, essas últimas, contribuíram em última instância para um melhor ambiente de vida nas cidades e foram, entre outros motivos, fomentadas pelas municipalidades também por isso. Na literatura, a regularização de moradias ilegais também foi vista, em parte, criticamente. Nela essa forma de uma autogestão patrocinada pelo estado foi entendida como uma falência do bem-estar estatal. Porém, os edifícios erguidos ou utilizados através de autogestão - sejam eles ilegais ou que estejam em conexão com construções cooperativas de moradias - possivelmente estejam em uma relação mais perfeita de adequação às necessidades de moradia do que aquela que uma construção estatal de moradias poderia realizar. Entretanto, coloca-se então imediatamente a pergunta sobre as necessidades de assentamentos. Concomitantemente, na autogestão fomentada oficialmente também se coloca a pergunta sobre quais são os direitos que aqui estão em jogo (cf. Marcuse 2009). Eles valem na mesma medida para todos? É legítimo que grupos específicos sejam contemplados porque para eles é aparentemente impossivel satisfazer suas necessidades por morada no mercado? Ou deveria ser fomentada a autogestão também daqueles a quem sua situação material permitiria satisfazer àquela necessidade? O que se torna questionável aqui é a necessária constituição, relacionada ao conceito "citizenship", de uma comunidade jurídica que se assenta sobre o princípio da igualdade. Aqui, no minimo, podem emergir tensões que não são tão simples de superar.

Diferentemente do mencionado caso especial do Brasil, o direito à cidade em países da Europa ocidental serve, sobretudo, como ponto de conexão para projetos culturais e políticos, para um uso coletivo de áreas até então desocupadas ou que tenham em vista o espaço público. Nesses casos, pode tratar-se de jardinagem urbana ou também de um projeto artístico. Frequentemente é também feito referência ao conceito de "commons", com o qual, como a linguagem deixa claro, é levantada uma reivindicação comunitária. Quem hoje tem acesso a projetos organizados comunitariamente, ou, no caso do solo, a seu uso coletivo, não está sujeito a qualquer regra estatal. Por conseguinte, permanece incerto quem está legitimado a aproveitar o commons. Aqui também se trata, pois, de iniciativas próprias e autogestão. Isso pode significar também a ocupação ilegal de solo e de edifícios. Porém, no caso de espaço ocupado por grupos específicos, não se trata de propriedade comunitária no sentido estrito, como a utilização do conceito "commons" sugere, já que 
ele também significa "bem comunal" (Allmende). ${ }^{10}$ Se, efetivamente, o bem comunal deve ser tomado como modelo histórico para isso, então dever-se-ia tratar a rigor de uma comunidade jurídica, a qual moldaria o espaço por meio de decisões tomadas coletivamente. Uma cooperativa poderia ser essa comunidade jurídica. Historicamente, o bem comunitário (Allmende) não era apenas usado e gerido comunitariamente, mas também era uma propriedade coletiva. Em uma ocupação, ao contrário, a propriedade sempre ainda se encontra na mão de uma outra pessoa, mesmo que seja o poder público. Se uma tal apropriação, todavia, for reconhecida pelos governantes, como pode se manifestar em uma política de aceitação da ocupação de casas vazias, e hoje em dia também cada vez mais no uso temporário contratualmente reconhecido de propriedades desocupadas, então abrem-se aqui, efetivamente, práticas de um direito ao solo reconhecido apenas por meio da práxis, mas que não é juridicamente codificado. Um dos motivos para isso é que morar não pode ser tão facilmente traduzido em uma mercadoria, o que, por sua vez, se deve a que se trata de uma necessidade básica. Em países como a Alemanha e a Suiça, contudo, a ocupação de casas é ainda juridicamente tipificada como violação de domicilio. ${ }^{11}$ Sendo assim, as formas coletivas de apropriação do espaço urbano não estão de saida inevitavelmente em conflito com a constitucionalidade e com os direitos dos outros? Não necessariamente: projetos artísticos, mesmo quando situacionalmente ferem regras, servem hoje nas cidades à valorização de espaços; daí que eles podem contar com aceitação por parte dos governantes. Procedimentos participativos também se aplicam a projetos artísticos. Um dos mais conhecidos exemplos disso é o monumento a Gramsci, de Thomas Hirschhorn, no
Bronx nova-iorquino no ano de 2013.12 Além disso, esse desenvolvimento leva a novas ligações entre investidores econômicos privados e construção comunitária ou cooperativa de moradias, que são de interesse para as cidades porque possibilitam a disponibilização de moradas mais baratas ao invés de especulação do solo movida por taxas de dividendos.

\section{Participação e direito à cidade em tempos de privatização}

Se agora, seguindo Beauregard e Bounds (2000, 248), sob o conceito de "urban citizenship" entendermos direitos e deveres que se concretizam relacionados a um "public realm" no qual os concernidos discutem suas questões coletivas e debatem sobre elas, então as diferentes vias de participação informal, como conferências e workshops, podem perfeitamente ser consideradas como práticas que devem ser apreendidas sob aquele conceito. Também aqui, como em qualquer forma de cidadania, o pressuposto é de que existam interesses públicos que demandam discussões e decisões políticas. Em uma cidade completamente privatizada, por exemplo, esses interesses públicos não mais existiriam. Nesse caso, a modelagem da vida social se consumaria somente com base em relações contratuais de direito privado. Isso pode bem representar uma utopia radicalmente mercadológica - e para muitos, antes, uma distopia - pois ainda não há um único exemplo nesse mundo no qual isso ocorra e que, assim, pudesse colocar à prova que, nessas condições, uma solução e uma administração de problemas pelas pessoas no local poderia se consumar objetivamente dessa maneira. ${ }^{13}$ Porém, com a globalização mudam também o significado das cidades e o agir de

\footnotetext{
10 Nota da tradução: Em alemão são designadas como "Allmende", "áreas de pastagem, bosques e terras inférteis, que foram separadas para uso econômico coletivo pelos residentes de uma associação de assentados que possuem esses direitos - residentes de uma ou mais vilas, aldeias ou agrupamentos" (Historisches Lexikon der Schweiz 2019).

11 A respeito das práticas e objetivos politicos das ocupações de casas em diferentes cidades europeias e norte-americanas, conferir Vasudevan (2017).

12 Art21 "Exclusive": Thomas Hirschhorn: "Gramsci Monument". Acessado em 18 maio 2018. https://www.youtube.com/watch?v=05yyegM2u88. 13 A demanda pelos assim chamados "commons", como colocada por novos movimentos sociais, parece diametralmente oposta à exigência de privatização radicalmente mercadológica de espaços públicos e de cidades inteiras. "Commons" significam apropriações coletivas de uso e propriedade coletiva. Porém, também no caso da propriedade pública do solo, trata-se fundamentalmente de propriedade coletiva de cidadãs e cidadãos, mas administrada estatalmente. Trata-se, precisamente, dessa terceira variante de propriedade coletiva já existente que hoje está ameaçada pela privatização, de modo que a demanda por "commons" pode ter impacto apenas limitado. Com o mencionado desenvolvimento, a questão de classe ganha novamente muito mais atenção.
} 
seus atores. Regiões urbanas não apenas entram em reforçada concorrência por empresas e força de trabalho. Por meio da formação de clusters econômicos, formam-se entre elas estruturas de divisão do trabalho. Assim, como Sassen (2001, 333) enfatiza, "global cities" assumiriam a coordenação do fluxo financeiro internacional, como ocorre em Frankfurt am Main.

Cidades representam hoje possibilidades lucrativas de investimento para o capital livremente circulante não por causa da possibilidade de comercialização do solo, mas também através da participação na construção de infraestrutura pública. Parques, prisões, trechos de rodovias e escolas são então propriedade de investidores privados, que alugam essas construções pensadas para o uso público ao poder público ou as operam eles mesmos. A primeira opção ocorre, na maioria das vezes, por meio das chamadas "private-public-partnerships". Quando o poder público dispõe de pouco caixa ou ainda quando a arrecadação de impostos não é suficiente, ele pode, apesar disso, prover a requerida infraestrutura e, ao mesmo tempo, na esperança de crescimento econômico, fomentar supostamente a extração privada de valor econômico por meio da qual novos mercados se desenvolvem no pais. ${ }^{14}$ Isso ocorre, entretanto, ao preço de que no longo prazo esse equipamento custará ao poder público muito mais do que se a infraestrutura estivesse em sua propriedade. Pois seria ilusório pensar que um investidor privado ali se envolveria nessa parceria sem a perspectiva de dividendos.

Porém, os centros de cidades não são atrativos apenas para investidores: eles também são atraentes para moradoras e moradores. Eles o são não apenas por causa das possibilidades de atividades econômicas e das variadas ofertas culturais, mas exatamente também pelas possibilidades de poder comodelar o próprio ambiente de vida, em sua própria vizinhança, por meio da participação. Os responsáveis por assegurar sua inclusão são os órgãos governamentais locais.
Porém, atualmente seu papel muda fortemente devido à maior importância de interesses privados na construção de infraestrutura pública - na Alemanha, por exemplo, também por meio de "contratos de planejamento urbano". Na esfera do planejamento urbano, isso significa um enfraquecimento de um "planejamento estratégico do desenvolvimento" em favor de uma "exploração territorial orientada por projetos" (Altrock 2009, 243). Para planejadores, segundo Uwe Altrock, em um ambiente assim resta apenas o papel de "dealmaker", "de usar investimentos privados, por exemplo em parcerias público-privadas, para financiar medidas positivas, as quais o poder público não (mais) empreende" (Altrock 2009, 243). Quando, então, organizações internacionais como a Organização das Nações Unidas (ONU), a UE e a OCDE postulam uma inclusão mais intensiva da população local através da política, esse apelo se depara com uma perda de poder das autoridades, que, nessas circunstâncias, devem simplesmente mediar entre interesses diversos, sem poder perseguir com vigor interesses públicos próprios ou estatais. Mas justamente ali nos centros urbanos se confrontam os diferentes interesses - de um lado aquele dos investidores, do outro aquele das moradoras e moradores economicamente ativos - e geram expectativas que nem sempre podem ser compatibilizados. Isso se torna especialmente claro quando se trata de incluir as preocupações das cidadãs e cidadãos na avaliação de grandes propostas de planejamento urbano. Como mostram nossos exemplos de pesquisa, uma mediação pelas autoridades e empresas privadas de comunicação e consultoria que agem em seu nome nem sempre é possivel e, em alguns casos, talvez também não é desejada.

\section{Alguns resultados adicionais da pesquisa}

Na investigação própria a respeito do tema da participação em projetos de planejamento urbano tratou-se, com base em entrevistas, de seguir a

14 Streeck em seu livro Gekaufte Zeit. Die vertagte Krise des demokratischen Kapitalismus menciona as parcerias público-privadas como uma prática que representa também uma possibilidade de financiamento antecipado para investimentos públicos quando estados estão comprometidos com uma "limitação de endividamento" (cf. Streeck 2013, 174, nota 22). 
trilha de possiveis novas compreensões sobre ser cidadãos, que pudessem se formar analogamente à constituição de uma cidadania local. A posição das cidadãs e dos cidadãos se refere sempre a um corpo político que, visto historicamente, terá surgido em concorrência com outras entidades comunais, como o kinship (parentesco) ou a cultiship (comunidade fundamentada na religião). $\mathrm{Na}$ cidade-estado ateniense, esse corpo político foi a cidade, enquanto um corpo territorialmente limitado, daí que seu significado na emergência da forma democrática de dominação seja reputado como relativamente alto. Será que a reconstrução da compreensão sobre ser cidadãos revela um retorno aos corpos menores? Isso, porém, mostra também que a compreensão sobre ser cidadão funda uma cultura política muito mais duradoura do que sugerem essas novas receitas de uma ativação neoliberal da sociedade civil, fundamentadas em última instância na figura de um homo economicus. Parece improvável que cidadãs e cidadãos participariam em um planejamento porque, assim, poderiam demonstrar seu ativamento, ainda que isso não poderia ser verificado empiricamente. Sua motivação naturalmente também não se constitui daquilo que as autoridades esperam da participação a saber, maior aceitação e legitimação para as decisões políticas. A aceitação surge somente quando ocorre previamente um equilibrio entre os diferentes interesses. Aqui os procedimentos de participação poderiam, fundamentalmente, desempenhar uma contribuição que correspondesse à teoria deliberativa. Porém, nos exemplos por nós investigados, isso ocorreu, em alguma medida, apenas nos exemplos suiços, ainda que pela via indireta das complexas teias do sistema político. A razão, nesse caso, são as possibilidades da democracia direta, sempre furtivamente presentes. Ao agir é levado em consideração que as cidadãs e cidadãos podem exercer sua influência nas decisões políticas devido a uma votação posterior sobre o projeto em questão. Nos exemplos vindos da Alemanha, prevaleceu antes a impressão de que encontrar solução de compromissos era irrelevante para as autoridades - como no planejado desenvolvimento na Mitte Altona em Hamburgo, no Kulturcampus em Frankfurt am Main e no Mittelmole na Warnemünde em Rostock. Um pouco diferente parece ser o caso de Heidelberg, onde existiam experiências prévias por parte das autoridades com participação dos cidadãos e, também, com votações conexas a projetos de construção. Além disso, através da compra do solo das Konversionsflächen (áreas antes ocupadas pelo exército dos EUA) a serem construídas, a municipalidade dispõe sozinha do poder de modelar a área. Quando uma cidade dispõe do terreno, isso naturalmente a coloca em uma situação vantajosa para poder atender a ideias e interesses das cidadãs e dos cidadãos e encontrar um equilibrio entre os diferentes interesses. Mas na maioria das vezes isso não ocorre, como, por exemplo, quando uma cidade como Hamburgo não adquire o terreno, mesmo que disponha do direito prioritário de compra. ${ }^{15}$ Ao contrário disso, a cidade de Berna agora quer comprar o terreno do Gaswerkareal. O governo da cidade fundamenta isso com o argumento de que deste modo poderão ser garantidas a mistura social e a qualidade de vida das pessoas que ali habitarão no futuro. Devido ao montante do valor a ser utilizado para a compra, os eleitores ainda precisarão decidir conclusivamente sobre isso.

Das entrevistas torna-se claro que os entrevistados em última instância conectam sua participação com a intenção de poder exercer influência sobre o arranjo de seu próprio ambiente de vida. Nesta participação estão em primeiro plano tanto a própria vizinhança como também a vizinhança futura. Nas conversas, os entrevistados ocasionalmente reclamam que quase não é tomado conhecimento de suas preocupações e discussões em outros bairros e, também, no

\footnotetext{
15 A cidade de Hamburgo dispunha desse direito porque havia classificado a área a ser reconstruída como uma "área de desenvolvimento" (sobre as medidas de desenvolvimento de reforma urbana, conf. \$165 et seq.. na parte sobre o direito especial do planejamento urbano do Baugesetzbuch, BauGB), o que, consequentemente, levou a um aumento do preço do terreno. Ao invés disso, o terreno foi adquirido por investidores, dos quais a cidade necessitará adquiri-lo posteriormente, por um preço mais alto, caso queira, por exemplo, usá-lo para um uso público ou a construção de moradias sociais.
} 
contexto da cidade inteira. O objetivo de nossa pesquisa foi o de reconstruir as concepções de democracia e as expectativas democráticas de pessoas engajadas. Nela esteve em primeiro plano o questionamento sobre em que medida eram expressas expectativas sobre a democracia nas falas dos entrevistados. Nas entrevistas, revelava-se alguma referência a um tipo de cidadania relacionado à moradia e ao lugar de vida? Se assume-se que participação informal seria uma prática democrática da construção política da vontade, então seria de se esperar que sim. A pesquisa revelou que muitas das pessoas engajadas entrevistadas esperam dos fóruns correspondentes que suas sugestões e ideias sejam aproveitadas, e isso com a justificativa de que elas seriam do interesse de todos. A reivindicação de que as preocupações sejam levadas em consideração é levantada, desse modo, com referência ao fomento de um bem comum. Porém, essa expectativa frequentemente dá em nada, especialmente porque não há qualquer obrigação por parte das autoridades quanto a levá-las em consideração. Não há qualquer vinculação de obrigação jurídica no sentido de que os resultados das discussões em fóruns de participação devam ser considerados finalmente no processo de decisão política. Se, porém, esse respeito fosse juridicamente vinculante, isso também seria novamente problemático, tanto na perspectiva da teoria democrática como na juridico-estatal, na medida em que, nesse caso, somente os participantes interessados poderiam exercer influência, o que seria contrário à universalidade do princípio da igualdade.

Devido às complicadas constelações nos respectivos planejamentos, essas gradativamente tornaram-se o foco da investigação. Por conta das divisões de trabalho e de tarefas entre autoridade e atores econômicos privados em cada situação, as competências se perderam parcialmente na incerteza, o que frequentemente levou a incompreensão por parte dos participantes, especialmente porque muitos haviam se engajado por anos e agora não conseguiam reconhecer qualquer resultado de seu engajamento. Devi- do à parcial opacidade e ininteligibilidade das competências de política, estado e economia nos projetos de construção pública em parceria com investidores, torna-se incerto quem de fato são os interlocutores das cidadãs e cidadãos para suas preocupações. Ainda que a relativização e a perda de importância da soberania de planejamento estatal possibilitem mais cooperação entre os atores, elas ao mesmo tempo levam a uma difusão das responsabilidades políticas (cf. Magnin 2017). Isso se constata tanto nos casos investigados na Alemanha quanto na Suiça, e essa questão é problematizada independentemente das concepções de democracia dos entrevistados. Ela coloca em xeque a democracia em geral.

No tocante à compreensão dos entrevistados sobre democracia, a pesquisa revelou basicamente dois diferentes tipos fundamentais, que podem ser novamente diferenciados em outro lugar: são dois tipos de engajamento dirigido à vizinhança comunitária. Assim, para a maioria dos entrevistados não se tratava de suas necessidades imediatas relativas à moradia, mas sim da modelagem de um ambiente de vida que disponha de qualidade de vida, o que por óbvio envolve concepções muito diferentes sobre como exatamente isso deveria ser realizado. Porém, suas demandas se revelaram como dirigidas a um espaço a ser moldado conjuntamente, o qual eles gostariam de modelar em discussão com outros. Essa reivindicação fundada em um modelo republicano de democracia conflitua fortemente com as privatizações constatáveis tanto do planejamento como do espaço público.

O segundo tipo fundamental de compreensão da democracia que reconstruímos é a concepção caracterizada como "liberal", de acordo com a qual a intenção de participar na modelagem relaciona-se mais às próprias quatro paredes, ou ao próprio projeto, do que à qualidade de vida no bairro. Isso, então, já corresponde quase à reivindicação de um consumidor do terreno e menos à de um cidadão que quer exercer influência. O entendimento liberal, ocorrido em minoria nas entrevistas e no qual a reivindicação por participação se limita sobretudo à garantia 
de direitos fundamentais em combinação com a possibilidade de poder participar regularmente nas escolhas de representações politicas, mostrou-se presente sobretudo naqueles casos em que havia a esperança de poder realizar um projeto próprio no âmbito do objeto em construção. Isso, porém, não apenas ocorre raramente, mas também deve ser visto, exemplarmente, antes em conexão com a dificuldade de assegurar a própria subsistência econômica.

\section{Balanço}

Sob as condições de uma economia capitalista, a democracia urbana e a vida em comum provam-se hoje em dia marcadas em especial medida por ambivalências. Para condições melhoradas de vida nas cidades faz sentido imediato que as moradoras e moradores se engajem e não deixem simplesmente a modelagem de seu ambiente de vida para investidores. Se fossem excessivamente orientadas pela extração econômica de valor, as cidades consistiriam de uma concatenação de objetos de investimento. Isso não gera qualquer vida urbana. Assim, alguns dos entrevistados temem, hoje, o surgimento de lugares urbanos doentios, que não parecem mais dignos de ser vivenciados. Mas eles querem viver ali, e isso junto com outros. Porém, tomar a consternação imediata de moradoras e moradores da cidade como ponto de partida para a futura modelagem do ambiente construido representa um desafio duplo. Aquela consternação constitui, de fato, o pressuposto para um ambiente em que vaIha a pena viver, mas se encontra em oposição diametral aos interesses dos investidores e, em muitos casos, não é compativel com eles. Essa problemática se torna ainda mais aguda quando as autoridades preveem a participação de cidadãs e cidadãos apenas como uma espécie de álibi para que os acertos com os investidores privados possam ser acelerados. Visto nessa perspectiva, seria certamente vantajoso se as formas de participação informal pudessem ser concretizadas e formalizadas juridicamente. E nelas autogestão e auto-organização de moradoras e moradores definitivamente deveriam ter lugar. Também elas contribuem para uma cidade em que valha a pena viver. Mas o importante é, sobretudo, que a politica como campo de ação e de práticas por meio das quais a formação democrática da vontade se realiza não escape às cidadãs e cidadãos ao ser relegada aos interesses econômicos.

Se a privatização da infraestrutura e dos espaços públicos seguir se multiplicando, então a decisão sobre como infraestrutura e espaços públicos deveriam ser constituídos será gradualmente retirada da discussão política e pública e, em última instância, também do poder político decisório. Em consequência, também desaparecerá o sujeito cidadão. As pessoas moradoras em um tal lugar seriam então apenas clientes que podem expressar seus desejos. Já nos casos por nós investigados, na visão dos entrevistados, frequentemente tratava-se menos de batalhar argumentativamente por uma solução do que de articular desejos individuais. Só que lhes permanecia frequentemente incerto a quem esses desejos deveriam ser dirigidos, particularmente quando investidores financiavam antecipadamente instituições e construções públicas e provedores privados mediavam fóruns de participação. No campo de ação do planejamento e do desenvolvimento urbano se revela o que também se mostra em outras áreas. Relações contratuais entram no lugar de vínculos, mas com isso também não pode mais haver qualquer identificação e engajamento pelo bem comum. E isso também não pode ser remediado por declarações de intenções e programáticas como uma ativação da sociedade civil, tal como são relacionadas à participação informal por parte dos atores políticos e científicos. Antes, é importante salvaguardar as condições para que cidadãs e cidadãos possam se engajar.

Relacionados à modelagem do espaço, direitos humanos e possibilidades de participação, efetivamente estão em uma relação específica um com o outro. Ao mesmo tempo, os direitos humanos, em seu significado como principios fundamentais, transcendem as possibilidades de participação e geram vínculos.

A desconfiança da população, cada vez mais clara em diversos países, frente tanto às elites 
quanto às instituições políticas dá oportunidade de se supor que com relação a esses vínculos e às regras de procedimentos democráticos a ela relacionados seria bom procurar por novos balanços e proporções entre possibilidades de participação representativa e direta, que desaguassem em uma cidadania assegurada por meio da constituição. A procura por novos caminhos não apenas está sendo prejudicada pela delegação de questões públicas e infraestrutura a interesses privados de extração econômica, mas também pela denúncia prematura de demandas correspondentes como conservadoras ou também como populistas, especialmente por aqueles que, sobretudo na Alemanha, se veem comprometidos exclusivamente com um modelo liberal de democracia, que assegura apenas possibilidades limitadas de participação para além da presença em eleições. De todo modo, e isso mostram os achados da pesquisa, o mecanismo de participação informal em projetos isolados, que da ótica da teoria liberal de democracia é concebido como um complemento significativo à democracia representativa, por si só não permite que se alcance a esperada legitimidade das decisões políticas. Para que sociedade e estado possam se encontrar em permanente troca, o que parece fazer sentido, procedimentos informais podem, de fato, ajudar, mas apenas como um complemento a direitos mais amplos de participação. Através de tais direitos e das práticas por eles legitimadas, a cidadania local poderia ganhar mais importância.

\section{Referências}

Albiez, Sarah, Nelly Castro, Lara Jüssen e Eva Youkhana, org. 2011. Etnicidad, ciudadania y pertenencia: practices, teoria y dimensiones espaciales. Madrid: Iberoamericana.

Altrock, Uwe. 2009. Gemeinwohlorientierung und Planungstheorie. In Im Interesse des Gemeinwohls: regionale Gemeinschaftsgüter in Geschichte, Politik und Planung, editado por Christoph Bernhardt, Heiderose Kilper e Tim Moss, 237-264. Frankfurt am Main: Campus.

Beauregard, Robert A. e Anna Bounds. 2000. Urban Citizenship. In Democracy, citizenship and the global city, editado por Engin F. Isin, 243-256. London: Routledge.
Benhabib, Seyla. 2006. Demokratische Iterationen: das Lokale, das Nationale, das Globale. In Kosmopolitismus und Demokratie: eine Debatte, editado por Seyla Benhabib, 43-71. Frankfurt am Main: Campus.

Benhabib, Seyla. 2016. Kosmopolitismus ohne Illusionen: Menschenrechte in unruhigen Zeiten. Berlin: Suhrkamp.

Blühdorn, Ingolfur. 2013. Simulative Demokratie: neue Politik nach der postdemokratischen Wende. Berlin: Suhrkamp.

Bosniak, Linda. 2000. Universal citizenship and the problem of alienage. Northwestern University Law Review 9 (3): 963-982. https://doi.org/10.2139/ssrn.232049.

Bosniak, Linda. 2006. The citizen and the alien: dilemmas of contemporary membership. Princeton: Princeton University Press. https://doi.org/10.1515/9781400827510.

Castles, Stephen e Alastair Davidson. 2000. Citizenship and migration: globalization and the politics of belonging. New York: Palgrave.

Chanial, Philippe. 2016. Ehre, Tugend und Interesse: Soziologien der Assoziation bei Tocqueville. In Alexis de Tocqueville: Analytiker der Demokratie, editado por Harald Bluhm e Skadi Krause, 291-391. Paderborn: Wilhelm Fink. https://doi.org/10.30965/9783846759547_014.

Dom, Catherine. 2012. Empowerment through local citizenship. In Poverty reduction and pro-poor-growth: the role of empowerment, editado por OECD, 107-136. Paris: OECD-Publishing.

Eibs Cafrune, Marcelo. 2016. Das Recht auf Stadt in Brasilien: Genese, Anspruch und Wirklichkeit des Rechts. Kritische Justiz 49 (1): 47-60. https://doi. org/10.5771/0023-4834-2016-1-47.

Fisahn, Andreas. 2013. Die neoliberale Umformung des Umweltrechts. In Neoliberalismus. Analysen und Alternativen, editado por Christoph Butterwege, Bettina Lösch e Ralf Ptak, 164-180. Wiesbaden: VS Verlag für Sozialwissenschaften. https://doi.org/10.1007/978-3531-90899-1_10.

Friendly, Abigail. 2013. The right to the city: theory and practice in Brazil. Planning Theory \& Practice 14 (2): 158179. https://doi.org/10.1080/14649357.2013.783098.

Grimm, Dieter. 2009. Souveränität: Herkunft und Zukunft eines Schlüsselbegriffs. Berlin: University Press.

Habermas, Jürgen. 1992. Faktizität und Geltung. Frankfurt am Main: Suhrkamp.

Harvey, David. 2008. The right to the city. New Left Review 53: 23-40.

Holston, James. 2008. Insurgent citizenship: disjunctions of democracy and modernity in Brazil. Princeton: Princeton University Press.

Inhester, Michael. 1998. Kommunaler Finanzausgleich im Rahmen der Staatsverfassung. Berlin: Dunker \& Humblot.

Jörke, Dirk. 2003. Re-Demokratisierung der Postdemokratie durch alternative Beteiligungsverfahren. $P_{O}-$ litische Vierteljahresschrift 54 (3): 485-505. https://doi. org/10.5771/0032-3470-2013-3-485. 
Kriesi, Hanspeter. 2005. Direct democratic choice: the Swiss experience. Lanhamh: Lexington.

Lefebvre, Henri. 2016 [1968]. Das Recht auf Stadt. Hamburg: Edition Nautilus.

Magnin, Chantal. 2017. Partizipative Politik und Verantwortungsdiffusion am Beispiel städtebaulicher Vorhaben. In Politik und Verantwortung: Analysen zum Wandel politischer Entscheidungs- und Rechtfertigungspraktiken. Sonderheft der Politischen Vierteljahresschrift, v. 52, editado por Christopher Daase, Julian Junk, Stefan Kroll e Valentin Rauer, 170-195. https:// doi.org/10.5771/9783845271934-171.

Marcuse, Peter. 2009. From critical urban theory to the right to the city. City 13 (2-3): 185-197. https://doi. org/10.1080/13604810902982177.

Marshall, Thomas H. 1992 [1950]. Bürgerrechte und soziale Klassen: zur Soziologie des Wohlfahrtsstaates. Frankfurt am Main: Campus.

Mayer, Margit. 2009. The 'right to the city' in the context of shifting mottos of urban social movements. City 13 (2-3): 362-374. https://doi.org/10.1080/13604810902982755.

Parsons, Talcott. 1969. Politics and social structure. New York: The Free Press.

Prigge, Rolf e Thomas Schwarzer. 2006. Großstädte zwischen Hierarchie, Wettbewerb und Kooperation. Wiesbaden: VS Verlag.

Sassen, Saskia. 2001. The global city: New York, London, Tokyo. Princeton: Princeton University Press. https:// doi.org/10.1515/9781400847488.

Schiller, Theo. 2011. Local direct democracy in Germany: varieties in a federal state. In Local direct democracy in Europe editado por Theo Schiller, 54-74. Wiesbaden: VS Verlag. https://doi.org/10.1007/978-3-531-92898-2_3.

Sintomer, Yves, Carsten Herzberg e Anja Röcke, eds. 2010. Der Bürgerhaushalt in Europa: eine realistische Utopie? Zwischen Partizipativer Demokratie, Verwaltungsmodernisierung und sozialer Gerechtigkeit. Wiesbaden: VS Verlag für Sozialwissenschaften. https://doi. org/10.1007/978-3-531-92176-1.

Streeck, Wolfgang. 2013. Gekaufte Zeit: die vertagte Krise des Kapitalismus. Berlin: Suhrkamp.

Suter, Andreas. 2004. Vormoderne und moderne Demokratie in der Schweiz. Zeitschrift für historische Forschung 31 (1): 231-254.

Vasudevan, Alexander. 2017. A history of urban squatting. Londonk: Verso.

Vatter, Adrian. 2014. Das politische System der Schweiz. Baden-Baden: Nomos-Verlagsgesellschaft.

Vetter, Angelika e Norbert Kersting. 2003. Democracy versus efficiency? Comparing local government reforms across Europe. In Reforming local government in Europe: closing the gap between democracy and efficiency, editado por Norbert Kersting e Angelika Vetter, 11-28. Opladen: Leske + Budrich. https://doi.org/10.1007/978-3-663-11258-7_1.
Vetter, Angelika e Norbert Kersting. 2003a. Reforming local government: heading for efficiency and democracy. In Reforming local government in Europe: closing the gap between democracy and efficiency, editado por Norbert Kersting e Angelika Vetter, 333-349. Opladen: Leske + Budrich. https://doi.org/10.1007/978-3-663-11258-7_16.

Wollmann, Hellmut. 2003. German local government under the double impact of democratic and administrative reforms. In Reforming local government in Europe: closing the gap between democracy and efficiency, editado por Norbert Kersting e Angelika Vetter, 85-112. Opladen: Leske + Budrich. https://doi.org/10.1007/978-3-663-11258-7_5.

\section{Chantal Magnin}

Doutora em Sociologia pela Universität Bern, Suiça, livre docente pela Leibniz-Universität Hannover, Alemanha; pesquisadora e professora de métodos da pesquisa social reconstrutiva no departamento de Economia da Hochschule Luzern, Suiça. 